\title{
Youth Unemployment in Mexico and Central America
}

\author{
Luis Rene Caceres ${ }^{1}$ \\ ${ }^{1}$ Independent Researcher, El Salvador \\ Correspondence: Luis Rene Caceres, 5456 Paseo General Escalón, San Salvador, El Salvador. E-mail: \\ luisrenecaceres@gmail.com
}

Received: July 8, 2021

doi:10.5539/ijef.v13n10p177
Accepted: September 21, 2021

Online Published: September 30, 2021

URL: https://doi.org/10.5539/ijef.v13n10p177

\begin{abstract}
The objective of this paper is to identify the variables that determine female and male youth unemployment rates, as well as female and male self-employment rates, in Mexico and Central American countries. The methodology of the analysis rests on the estimation of VAR models with panel data from the period 1990-2018. The results indicate that there are gender differences in the behaviour of unemployment and self-employment rates: remittances increase female unemployment, but not male unemployment; the human development index and economic growth rate reduce male unemployment, but not female unemployment. In addition, female and male self-employment rates fall with the rise in the human development index, but only the male one falls to rising economic growth. These results had not been reported in the literature. The paper also presents a review of labor market developments in Latin America associated with the Covid pandemic. The main recommendation from this paper is that social policies related to unemployment must take explicit steps to address the difficulties young women face in the labour market. This paper is original since there are very few studies of youth unemployment for Latin American countries; it is the first to be based on the estimation of VAR models. The work concludes with a number of policy recommendations that should be put in place to combat the "culture" of abuse and discrimination faced by women in the labour market.
\end{abstract}

Keywords: unemployment, self-employment, gender inequality, labor market

\section{Introduction}

The analysis of youth unemployment (that experienced by the population between 15 and 24 years), has received considerable attention in recent years. This interest lies in the high rates that youth unemployment attains in many countries, being two or three times the magnitude of adult unemployment. The interest also stems from the impact of youth unemployment in terms of the loss of human capital and economic growth. Several authors have shown that youth unemployment is a preamble to self-employment, that is, to informality (Caceres, 2021a).

This work analyzes the variables that have an impact on youth unemployment in Mexico and Central America, using VAR models estimated with panel data for the period 1990-2018 for Mexico, Guatemala, El Salvador, Honduras, Nicaragua, Costa Rica, and Panama. VARs are also estimated to identify the variables that determine self-employment in these countries. The models include labor market and other variables, such as remittances received by countries and their Human Development Indices, HDI. The next section presents a review of the selected literature on the subject, which is followed by a discussion of the variables that are assumed to be associated with youth unemployment. Next, the topic of the data used in the research and its statistical properties is addressed. This is followed by discussion of the responses of the youth unemployment and self-employment rates to increases in the other variables. In subsequent sections the repercussions of youth unemployment, the importance of taxation, and the effects of the Covid pandemic on the labor markets of some countries for which data is available are discussed. Although the analysis of the devastation in the labor market as a result of the Covid does not cover all countries or the entire year of 2020, the data presented show that the pandemic has affected youth and women to a greater degree, as well as people with low levels of education. The work ends with a series of conclusions.

\section{The Data and Its Properties}

The different VAR models were estimated with qualitative variables to represent the countries, except Mexico, and thus control the fixed effects, which is a common practice in the literature.

The data source is the World Bank's World Development Indicators. The average values and standard deviations 
of the variables are shown below in Table 1 .

Table 1. Average and standard deviations of variables

\begin{tabular}{lcc}
\hline Variable & Average & Standard deviation \\
\hline Exports* & 36.2734 & 15.4550 \\
Remittances* & 6.6852 & 6.5307 \\
Female youth unemployment & 11.3768 & 5.0588 \\
Male youth unemployment & 8.1890 & 3.8815 \\
Female self employment & 42.0750 & 13.0971 \\
Male self employment & 32.0300 & 7.5518 \\
Economic growth & 3.7795 & 2.5778 \\
Human Development Index & 0.6509 & 0.0824 \\
\hline
\end{tabular}

\section{Selected Literature Review}

Most of the studies on youth unemployment are based on applications of Okun's law, except for two recent works. Choudhry, Signorelli, and Marelli (2011) used data from 75 countries to estimate panel equations reporting that youth unemployment increases with events of financial crisis and falls with increases in economic growth and inflation rates, while Torres and McKenzie (2020) analyzed youth unemployment in six Latin American countries using household survey data, reporting that as young people's education, or age, increased, youth unemployment decreased. In Latin American countries, youth unemployment may be a preliminary step for young people to engage in illegal activities, to opt for irregular emigration, or to decide to enter the bulk of the young population that neither studies or work, the so-called NEETS. In the case of Honduras, Cáceres (2021b) presents evidence that youth unemployment leads to an increase in the NEET population, and to drops in productivity and in the economic growth rate.

Youth unemployment is especially important because of its incidence in violence (Chioda, 2017), because of its role in undermining governance (Giuliano \& Spilimbergo, 2009) and because of its persistence, which is more pronounced than unemployment among people over the age of 24 , according to the evidence presented by Scarpetta, Sonnet, and Manfredi (2010), Ryan (2001), and Caporale and Gil-Alana (2014). Another characteristic of youth unemployment is that its values are higher than those of people over 24 years of age, which Dunsch (2016) has explained by pointing out that youth employment is concentrated in the industrial sector that is highly susceptible to the economic cycle. Furthermore, given their lack of experience, companies do not incur losses when they lay off young employees (Banerji, Lin, \& Saksonovs, 2015). The fact that young people are employed with temporary contracts facilitates their dismissal (Scarpetta, Sonne, \& Manfredi, 2010). With the exception of Hutengs and Stadtmann (2016) and Banerji, Lin, and Saksonovs (2015), studies for developed countries do not disaggregate the analysis of youth unemployment by sex.

Regarding self-employment, which is an indicator of the informal economy, reference can be made to the evidence presented by Caceres (2017a) for 8 Latin American countries that self-employment falls with the increase in the economic growth rate, and that it increases with the increases in the unemployment rate and the ratio of remittances to GDP. This author also reported that informality increased with inequality in the distribution of income and decreased with the increase in real wages. In another study, Caceres (2017b) reported that informality decreased with the increase in tax revenues as a percentage of GDP, and that the fall in informality led to an increase in international reserves per capita, given the role of informality in increasing economic volatility.

\section{Identification of Variables Associated with Youth Unemployment}

Exports enter the VAR by virtue of the fact that they represent high percentages of GDP in the countries under study and, therefore, it can be assumed that their increase would lead to employment growth. The same can be said of remittances, which in all countries except Mexico, Costa Rica, and Panama represent high percentages of GDP, around 12 percent in Nicaragua and Guatemala, and 20 percent in Honduras and El Salvador. By virtue of the high percentage that informality represents in the countries, between 40 and 50 percent, the rates of female and male self-employment are also included in the VAR. There is evidence that in Latin American countries informality is a source of employment of last resort for the unemployed (Cáceres, 2017a). To quantify the role of human capital in unemployment, the Human Development Index is included in the VAR, which is computed as the weighting of the per capita GDP, life expectancy at birth, which is related to the quality of services of health, and the average level of education of the respective country. A study on the variables that determine this index 
found that it was a reflection of per capita social expenditure of the country in question (Cáceres, 2008). The economic growth rate, Growth, is also included, which makes it possible to verify whether Okun's law prevails in these countries. Next, the youth unemployment rate enters the VAR, followed by the female self-employment rate, which is the most endogenous variable.

The first VAR to be estimated is the following: (Remittances, Exports, HDI, Growth, Youth unemployfeme, Autoemployfeme). In this specification, the most exogenous variable is remittances, followed by exports, the human development index and the economic growth rate, followed by the female youth unemployment rate and the female self-employment rate, which, as noted, the latter is the most endogenous variable.

\section{Results}

\subsection{Female Youth Unemployment}

Figure 1 shows the responses of the female youth unemployment rate to shocks of one standard deviation to the other variables. It can be seen that female youth unemployment increases significantly in response to the increase in remittances throughout the period. This is an unexpected result that can be related to the conclusions of several authors who found that remittances had no role in boosting economic activity. The female youth unemployment rate falls with the increase in exports, which reflects the positive impact of exports on GDP growth according to an extensive literature, and the close relationship between maquila exports and female labor. The response to the increase of the HDI is not significant, which is unexpected given that human capital offers a "shield" to people against unemployment (Azkenazy, Chevalier, \& Erhel, 2015). Therefore, calls to public officials from different countries to give priority attention to the educational performance of girls and young women may be insufficient if the national policies are not put in place to help female workers to have a better performance in the labor market. It should be noted that in Latin American countries in recent years the average levels of education of young women exceed that of young men, however, the youth unemployment rates of girls and young women are higher than those of young men.

It is observed that, given the increase in economic growth, the female youth unemployment rate has a negative response, but it is only significant in the first three years, so it could be inferred that Okun's law does not apply to unemployed female youth. The response to the increase in the female self-employment rate is positive and significant only in the first two years, that is, informality does not offer a "refuge" to unemployed young women.

Accumulated Response to CholeskyOne S.D. Innovations \pm 2 S.E.

Accumulated Response of YOUTHUNEMFEME to REMITTANCES

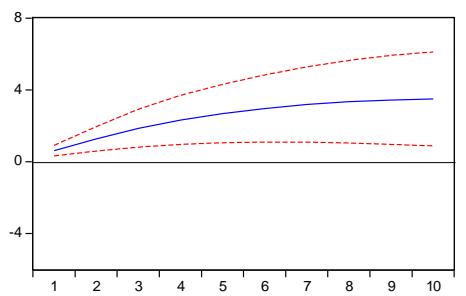

Accumulated Response of YOUTHUNEMFEME to HDI

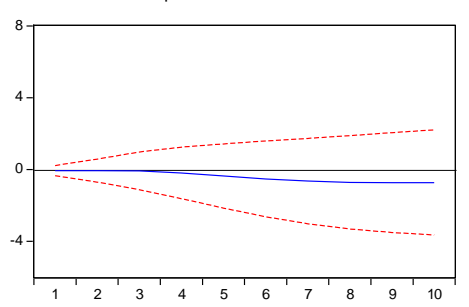

Accumulated Response of YOUTHUNEMFEME to AUTOEMPLFEME

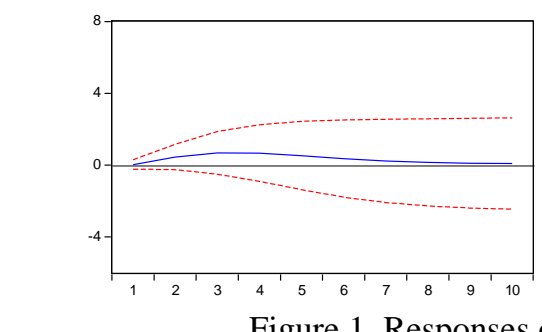

Figure 1. Responses of female youth unemployment
Accumulated Response of YOUTHUNEMFEME to EXPORTS

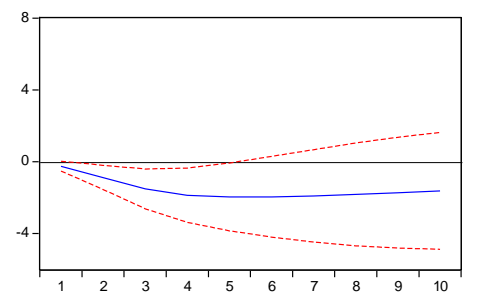

Accumulated Response of YOUTHUNEMFEME to GDPGROWTH

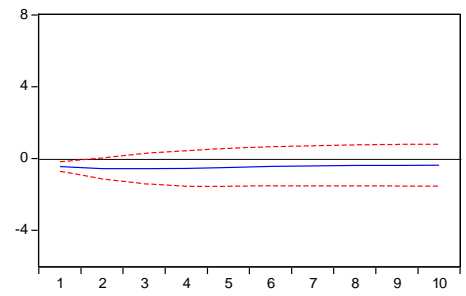




\subsection{Male Youth Unemployment}

Figure 2 shows the responses of the male youth unemployment rate. It is observed that the response to the increase in remittances is positive, but it is significant only in the first two years, which contrasts with the persistent increase experienced by the female youth unemployment rate, as shown in Figure 1. That is, the situation of unemployed young men does not worsen or improve in relation to an increase in remittances. The response to the increase in exports is negative, that is, male youth unemployment falls as a consequence of the dynamism of exports, a behavior similar to that of female youth unemployment. It is striking that the response to the increase in HDI is negative and significant, which contrasts with the absence of a significant response from female youth unemployment. While human capital helps young males overcome unemployment, this is not the case for young women.

Male youth unemployment falls permanently with increased economic growth, contrary to what was observed in the case of female youth unemployment. That is, for young males there is an Okun law. This highlights the importance that studies of youth unemployment using Okun's law disaggregate the analysis by sex. Contrary to the case of female youth unemployment, male youth unemployment shows a significant drop in response to the increase in the male self-employment rate. This implies that for unemployed young males there is a place in informality, while informality is "saturated" for young females.

Accumulated Response to CholeskyOne S.D. Innovations \pm 2 S.E.

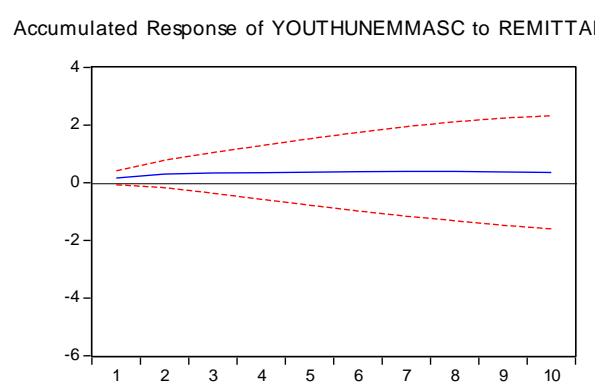

Accumulated Response of YOUTHUNEMMASC to HDI

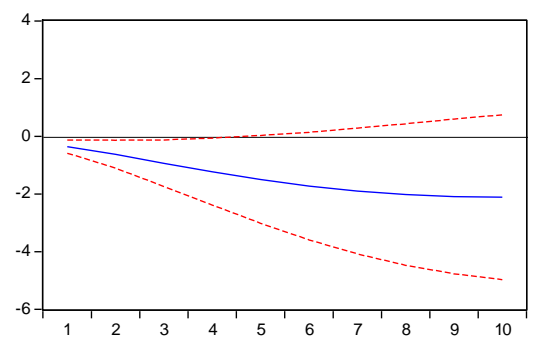

Accumulated Response of YOUTHUNEMMASC to AUTOEMPLMASC

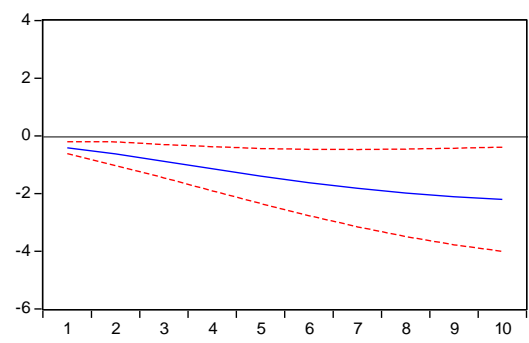

Figure 2. Responses of male youth unemployment

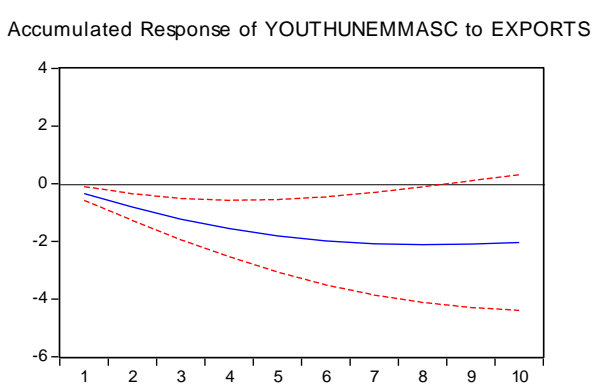

Accumulated Response of YOUTHUNEMMASC to GDPGROWTH

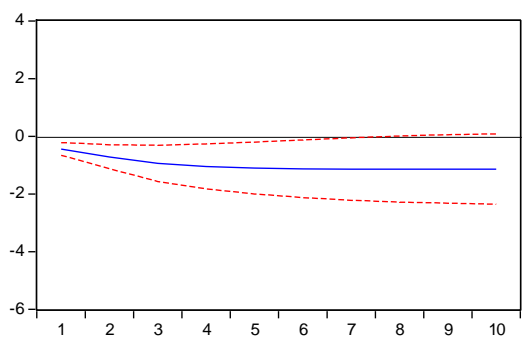

\subsection{Differences Between Female and Male Youth Unemployment}

The previous results, which showed divergences between the responses of the female and male youth unemployment rates, indicate the existence of elements outside the labor market that obstruct female employment, which could reflect a "culture" of discrimination against young women. It should be noted that the unemployed young woman can find an occupation at home, for example in working for the family, which "ties" her to unemployment, since she must fulfill her role of being a caregiver at home. That is, her "employment" in home care may inhibit her efforts to overcome her unemployment situation. On the other hand, the single mother 
who is working may leave her job when she receives remittances to dedicate herself to caring for the children. Eventually this can lead young women to withdraw from the job market. It should be noted that the percentages of female NEETs in the countries included in this study, except Costa Rica and Panama, are the highest in Latin America.

The results shown in Figures 1-2 indicate that youth unemployment responds to the behavior of specific variables; therefore, it is not valid to argue that the high rates of youth unemployment are a reflection of the inclination of young people to "shop around", that is, to "tinker" with different kinds of employment until they find the one that best suits them. In the absence of discrimination against young women, the female youth unemployment rate would be equal to the male rate, for the same levels of education and skills. The difference between these rates represents the behavior of female youth unemployment after eliminating the common effects with the male one, that is, it is what is "left over" after eliminating the "normal" behavior, free of prejudices, in the labor market. If this response is not significant, or is of a low dimension, then it could be deduced that there is no discrimination against young women in relation to their responses to increases in specific variables.

The responses shown in Figure 3 allow us to deduce that remittances give rise to a positive and significant response in the difference between young female and male unemployment; the same is observed in relation to the response to the increase in female self-employment, and in relation to the increase in the HDI in the first 5 years. In these cases, the responses of the differences are positive and significant, which means that female youth unemployment are subject to a special "regime". It should be noted that the response to the increase in the economic growth rate is negative and marginally significant, implying that the validity of Okun's law is subject to aspects of gender discrimination. This "regime" may consist of job discrimination, and it may also represent the "culture" of abuse against women. Therefore, to improve the employment situation of young women it is necessary to resort to deliberate institutional measures.

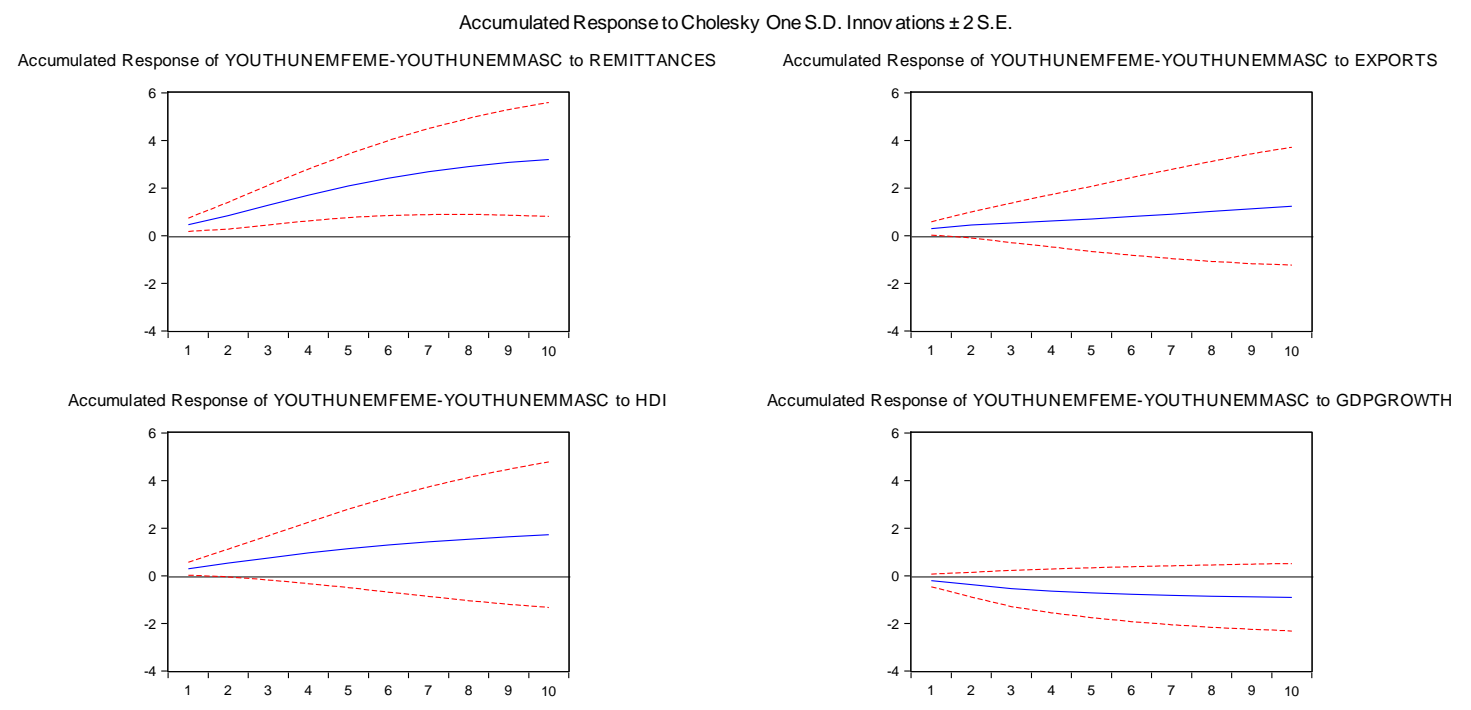

Accumulated Response of YOUTHUNEMFEME-YOUTHUNEMMASC to AUTOEMPLFEME

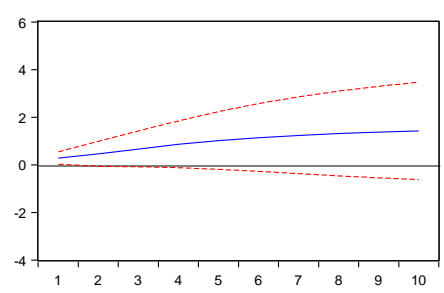

Figure 3. Responses of difference between female and male youth unemployment.

\subsection{Female Self-Employment}

Figure 4 shows the responses of the female self-employment rate, that is, female informality. The response to the increase in remittances is positive and significant only in the first three years. The response of female self-employment is negative in relation to the increase in exports, that is, exports offer employment opportunities to women that allow them to get out of informality. Of special importance is the negative response of female self-employment to the increase in HDI, which denotes that human capital is a "shield" that protects women 
from entering the informal sector. The response regarding the increase in economic growth is slightly negative and not significant. This would indicate that female self-employment is so rooted in informality that it does not respond categorically to increases in economic growth. This situation could be interpreted as a manifestation of the difficulties of women to have access to good jobs and to get out of the informal sector.

The increase in female youth unemployment gives rise to a response that is not significant; this could be interpreted as a situation in which female informality is "saturated" and does not accommodate young unemployed women. It should be noted that Buenhn and Scheneider (2012) and Caceres (2017a) have reported that the unemployment rate has a positive effect on increasing the dimension of informality.

Accumulated Response to CholeskyOne S.D. Innovations \pm 2 S.E.

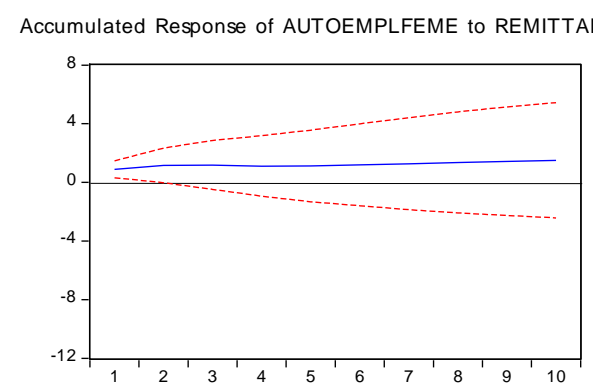

Accumulated Response of AUTOEMPLFEME to EXPORTS

Accumulated Response of AUTOEMPLFEME to HDI
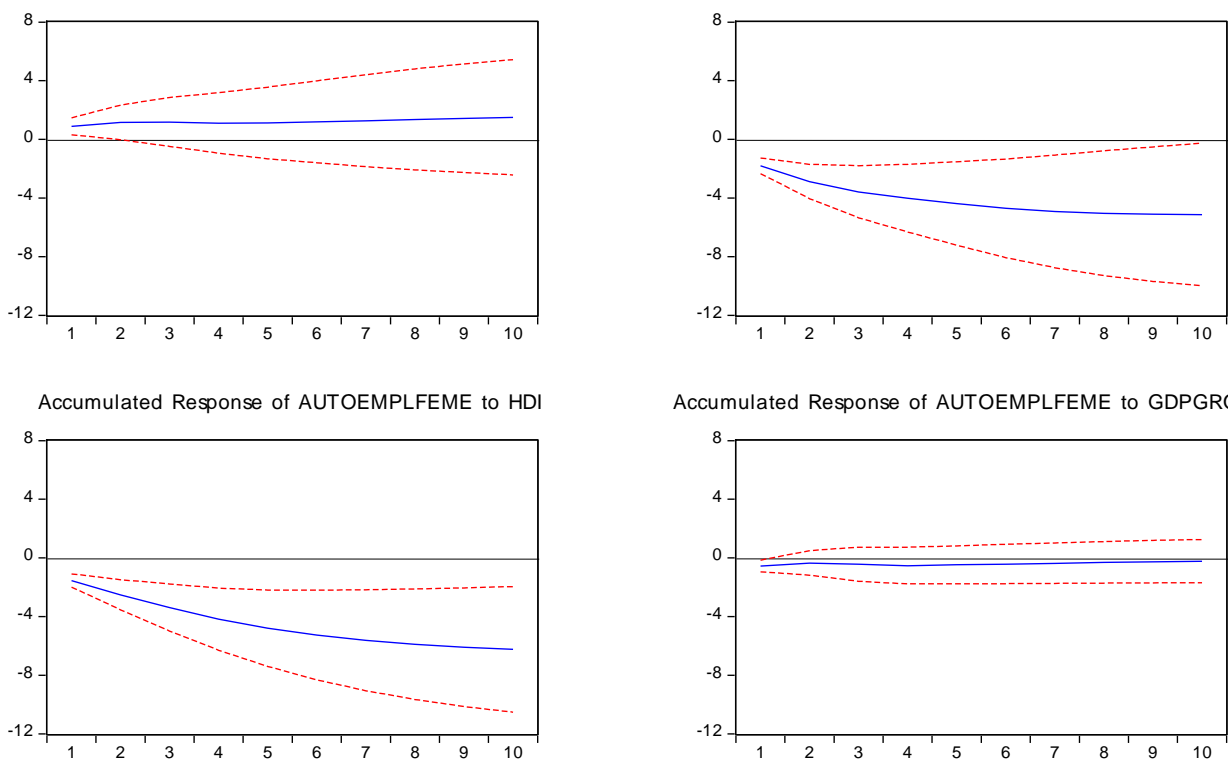

Accumulated Response of AUTOEMPLFEME to GDPGROWTH

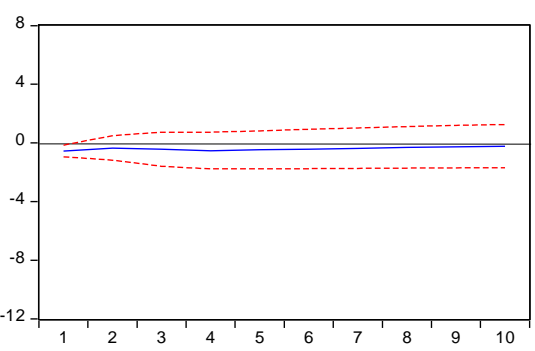

Accumulated Response of AUTOEMPLFEME to YOUTHUNEMFEME

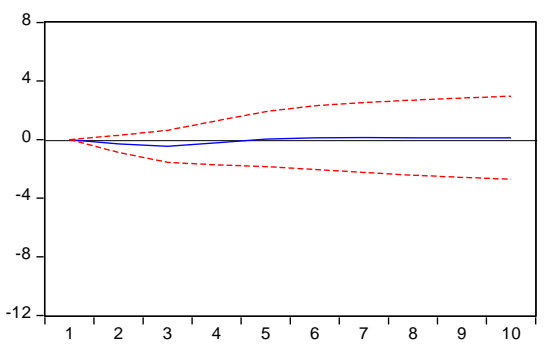

Figure 4. Responses of female self-employment

\subsection{Male Self Employment}

Figure 5 shows the responses of male self-employment. It is observed that male informality experiences a slight fall due to the increase in remittances, which is significant in the first four years, contrary to the increase in female informality observed in figure 4. This is another reason why studies on the impacts of remittances on the labor market must disaggregate the data by sex. The response regarding the increase in exports is negative and significant, indicating that, as in the case of the female self-employment rate, exports reduce male informality. Also, as in the female case, male informality falls with the increase in HDI.

Contrary to that of women, male informality falls significantly due to the increase in the economic growth rate in the first five years, which indicates that male informality is not voluntary, it is not a response to avoid a high tax rate, nor is it to have a flexible work schedule, as has been indicated in the literature, but it is the result of a decision of employment of last resort in the absence of better employment opportunities. The reduction in male self-employment due to increases in economic growth and tax revenues has also been detected in a sample of Latin American countries (Caceres, 2017a). 
Accumulated Response to CholeskyOne S.D. Innovations \pm 2 S.E.

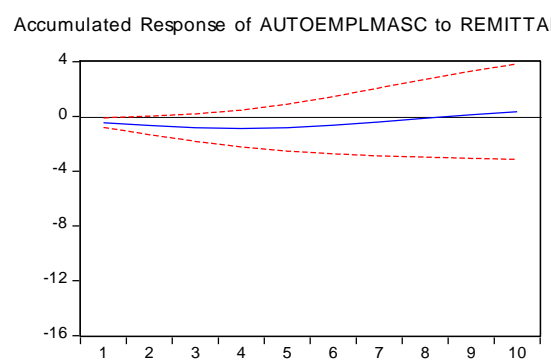

Accumulated Response of AUTOEMPLMASC to HDI

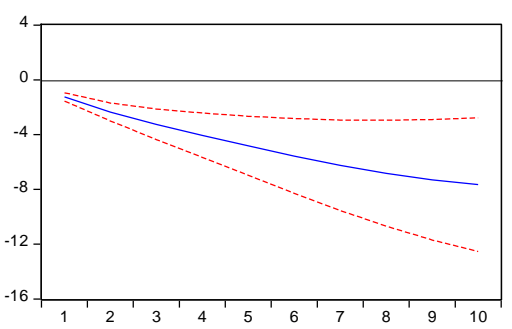

Accumulated Response of AUTOEMPLMASC to EXPORTS

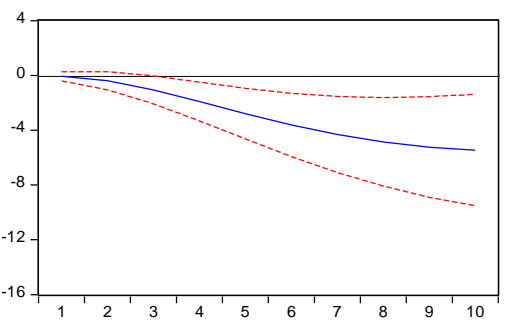

Accumulated Response of AUTOEMPLMASC to GDPGROWTH

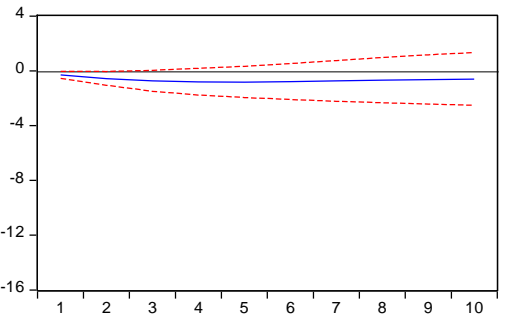

Accumulated Response of AUTOEMPLMASC to YOUTHUNEMMASC

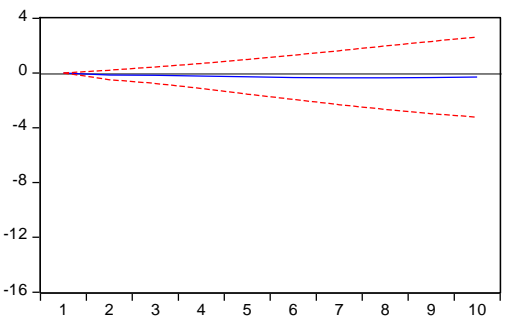

Figure 5. Responses of male self employment

\subsection{The Additional Worker}

A model was estimated to verify whether the "additional worker" phenomenon exists in the countries included in this study, according to which, when a member of the household, generally the head of the household, becomes unemployed, another member of the family enters to the labor market to compensate for the loss of household income. This phenomenon has been detected in several Latin American countries (Parker and Skoufias, 2004; Paz, 2009). Figure 6 shows that the female employment to population ratio responds positively and significantly to the increase in male youth unemployment. This means that women compensate for the loss of income caused by the increase in male youth unemployment, thus assuming a role as a "social safety net", particularly as "insurance" against unemployment. This mechanism could lead to negative repercussions for women since, in their role as protectors of the household, they could abandon their studies, or the situation could reach a degree in which children have to enter the labor market,

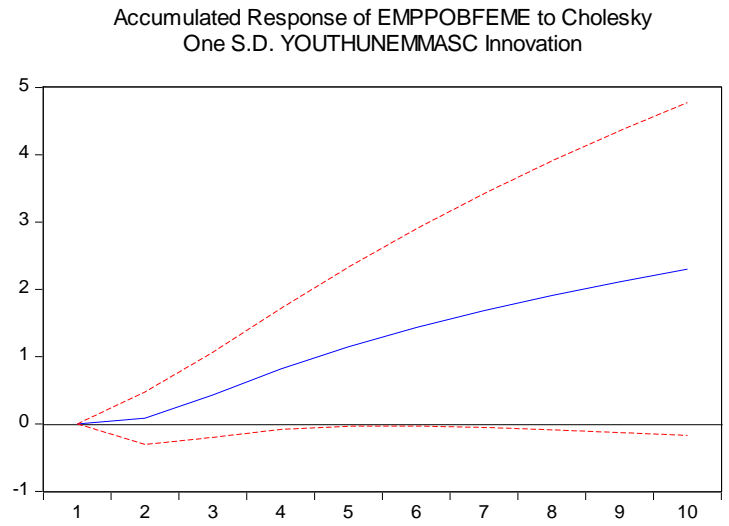

Figure 6. Response of ratio of female employment to population to increase in male youth unemployment 
However, the opposite occurs when female youth unemployment increases, as shown in Figure 7, in the sense that there is a drop in the ratio of male employment to population. In other words, the increase in unemployment of young women leads men to withdraw from the labor market, which could be explained by the acquisition by the household of "free" female labor that takes over household work, thus alleviating the family budget. In other words, in this case the young women grant the household an in kind "transfer" of free labor.

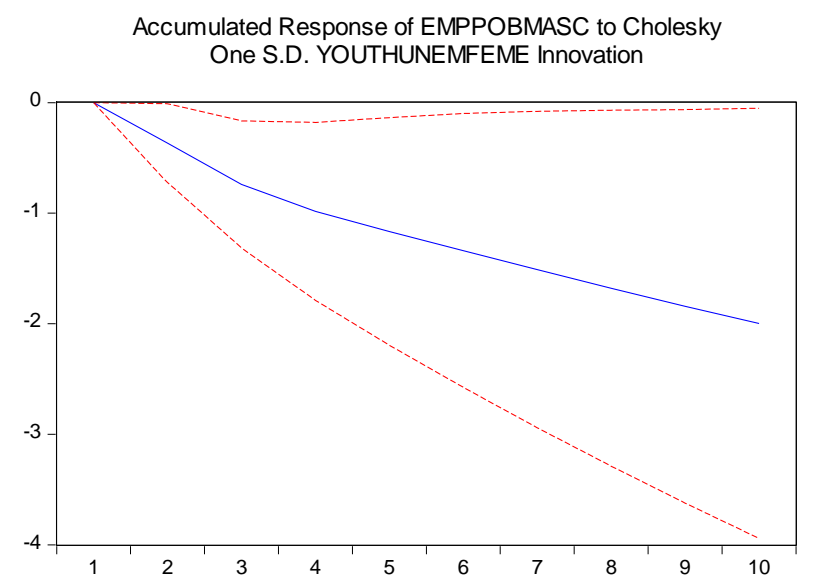

Figure 7. Response of the male employment to population ratio to the increase in female youth unemployment

\section{Repercussions of Youth Unemployment}

Reference must be made to the evidence that youth unemployment can generate outbreaks of violence, as pointed out by Chioda (2017). de Hoyos, Gutiérrez Fierros and Vargas (2016) attribute the increase in violence in Mexico to the repercussions of the global crisis of 2008-2009, which resulted in a 6 percent contraction of the Mexican economy and an increase in youth unemployment, in desertion from school, and in the increase in the percentage of male NEETs. In other words, in the absence of employment in the formal sectors, youth had to engage in illegal activities. Caceres (2017c) has presented evidence for a sample of Latin American countries that youth unemployment is associated with self-employment and violence. Figure 8 shows that in El Salvador the male youth unemployment rate with a 5-year lag has a positive relationship with the male self-employment rate. A relationship is observed in Honduras between the female youth unemployment rate with a lag of 7 years and the female self-employment rate (Figure 9).

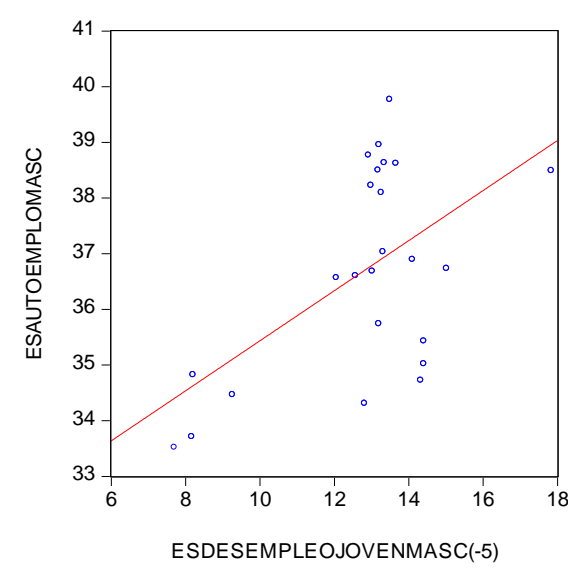

Figure 8. Male youth unemployment rate (esautoemplomasc) with 5-year lag and male self-employment rate in El Salvador

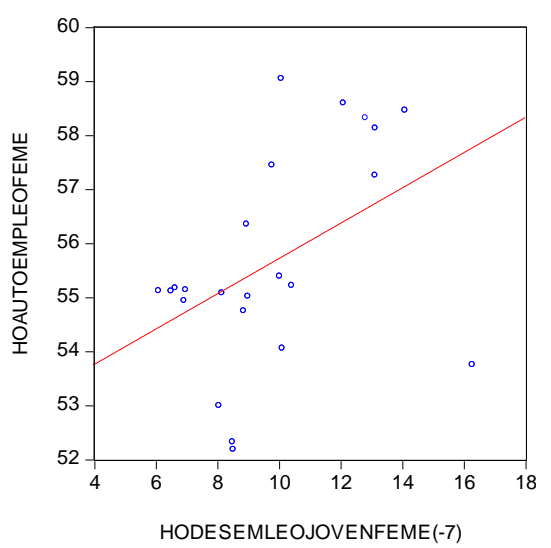

Figure 9. Female youth unemployment rate (hoautoempleofeme) with a 7-year lag and female self-employment rate in Honduras

The point that should be emphasized is that there is a very close correlation between male self-employment, (autoempleomasc2010), and the number of homicides per 100,000 inhabitants in 13 Latin American countries (Cáceres, 2017c), as shown in the Figure 10 with data from 2010. 


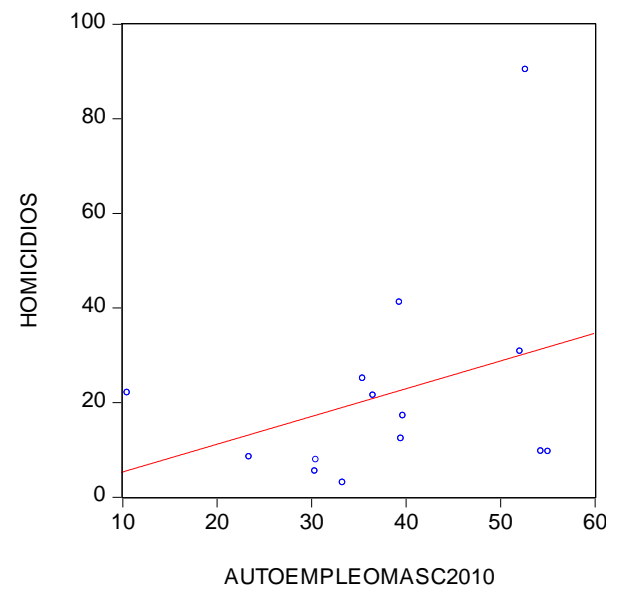

Figure 10. Female self-employment rate and number of homicides per 100,000 inhabitants.

Figures 8 and 9 show that in Latin American countries youth unemployment can lead to self-employment, and thus to an increase in the homicide rate (Figure 10).

Given the evidence presented in Figure 5 that the increase in HDI leads to a fall in self-employment, it follows that despite the severe ravages of COVID-19 on public finances, it is currently necessary to maintain and increase the support of the public sector to the expansion of health and education services, with a view to combating and preventing youth unemployment, informality and violence. Otherwise, COVID-19 may result in another pandemic, that of violence. But this requires substantial increases in tax revenues.

\section{Role of Taxation}

It should be noted that self-employment is related to historical deficiencies in the supply of social services, as reported by Caceres (2017b). Figures 11 and 12 present relationships for a sample of 18 Latin American countries between the 1960 enrollment rate in secondary education as a percentage of the corresponding age, taken from the World Bank's 1984 World Development Report, and the corresponding 2010 female and male self-employment rates. This indicates that self-employment, that is, employment in the underground sector, is a manifestation of deficiencies in people's education. Given that self-employed people tend to be in a situation of poverty (Caceres, 2017b) and do not have the resources for their daughters or sons to have access to a quality education, self-employment can be transmitted from generation to generation.

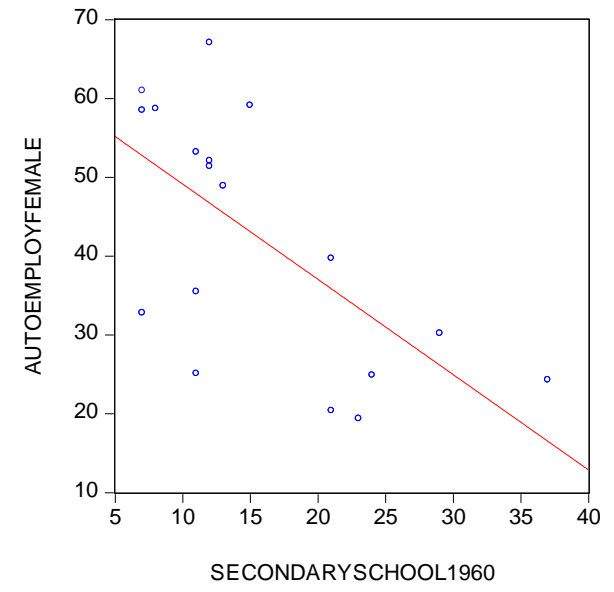

Figure 11. Secondary education enrollment in 1960 and female self-employment rate in 2010

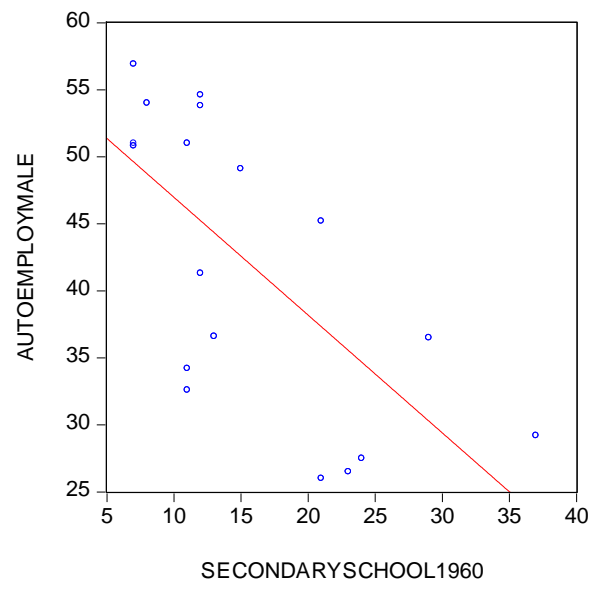

Figure 12. Secondary education enrollment in 1960 and male self-employment rate in 2010

What explains the low level of secondary education in some Latin American countries is their low tax revenues; Figure 13 shows the existence of a negative relationship between the tax revenues as a percentage of GDP in 1972, taken from the World Bank's World Development Report 1984, and the female self-employment rate in 2010. 


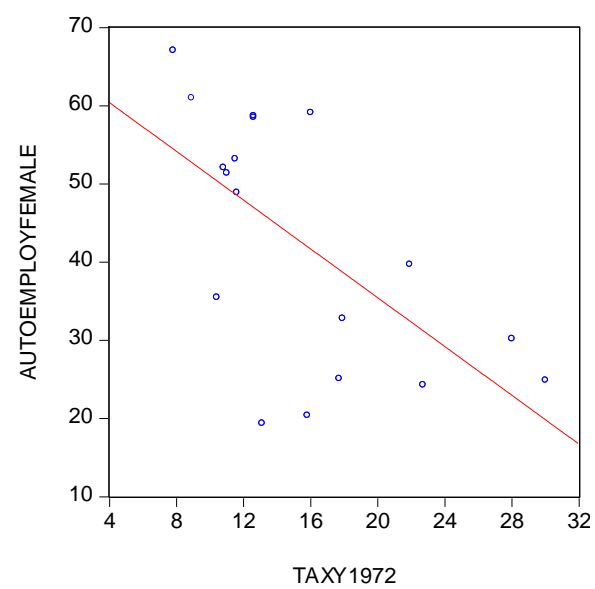

Figure 13. Tax revenues as a percentage of GDP in 1972 and rate of female self-employment in 2010

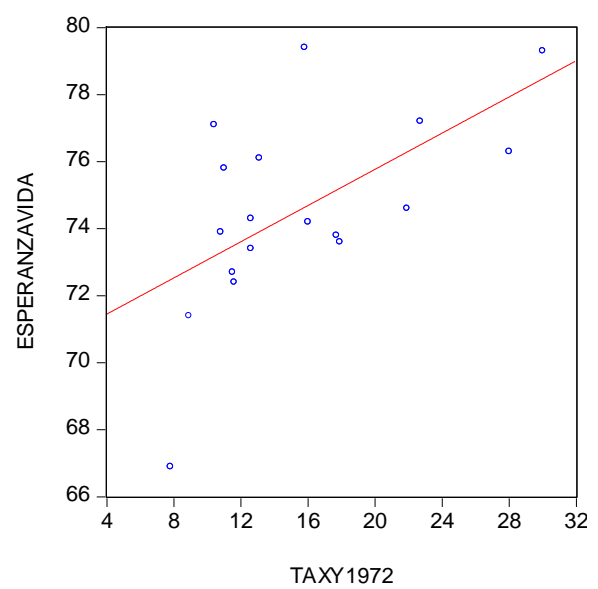

Figure 14. Tax revenues as percentage of GDP collection in 1972 and life expectancy at birth

This Figure indicates that the low tax revenues in 1972 did not allow the expansion of educational coverage, or the improvement in the quality of education, necessary to achieve educational attainment that would have allowed high percentages of students to obtain good jobs and, therefore, subsequently give their daughters and sons a good education. The low taxation resulted in large segments of the population having low levels of education, so that their daughters and sons, and their descendants, did not have adequate education either, and thus their future became working as self-employed as their ancestors. Of special relevance is the positive relationship observed in Figure 14 between tax revenues in 1972 and life expectancy in 2010 (esperanzavida):

Since the 1972 taxation is related to self-employment (Figure 13), it follows that self-employment is related to premature death, and that both are associated with low tax collection. Thus it is valid to infer that low taxation kills.

\section{Repercussions of the Covid Pandemic on Employment}

In preparing this paper, no data was available for 2020 on the behavior of the labor market in the countries included in the sample, and data were only found for some aspects of the labor market in the first two or three quarters of that year. According to ECLAC data (2021a), the COVID pandemic has had different effects for women and men in relation to employment. At the regional level, in the second quarter of 2020 the female unemployment rate was 22.2 percent, an increase of 12.6 percentage points compared to 2019, and higher than the percentage corresponding to men, of 15.1 percent. The high unemployment rate for women is explained by the fact that 57 percent of women are employed in sectors highly susceptible to the ravages of the pandemic, such as commerce, hospitality, tourism, and manufacturing. The female unemployment rate translates into 118 million women living in poverty and a reduction in the labor participation rate back to 10 years ago.

Data from January to September 2020 published by ECLAC (2021b), of the participation rates of the countries for which data are available, show that the falls in female participation have been more marked than that of males. The reductions in female participation are explained by the departure of women from the labor market to dedicate themselves to the care of their children. In an analysis of the labor markets of 20 developed and developing countries, Bluedorn et al. (2021) found that women had experienced greater reductions in the participation rate than men, and that these differences explained the differentiated impacts by gender of the Covid pandemic.

Table 2. Female and male participation (January-March)

\begin{tabular}{llll}
\hline Country & & 2019 & 2020 \\
\hline Mexico & Female & 44.5 & 40.4 \\
& Male & 74.2 & 72.2 \\
Costa Rica & Female & 50.5 & 47.8 \\
& Male & 74.2 & 72.2 \\
Nicaragua & Female & 61.1 & 58.4 \\
& Male & 82.2 & 80.4 \\
\hline
\end{tabular}


Data corresponding to April-June 2020, in relation to the same quarter of 2019, published by ECLAC (2021c) for eight Latin American countries, show that the pandemic has led to more pronounced job losses for the young population between 15 and 24 years than for the population over 24 years of age. Only one country in the sample of this paper is found in that ECLAC publication; in Costa Rica, young women suffered a drop in employment of 38.8 percentage points, while for young men the drop was 23.3 percent. For the population between 24 and 35 years of age, the corresponding falls were 29.9 percent for women and 20.8 for men. This indicates that the young population has suffered the attacks of the pandemic more severely than the adult population and that within the young population female workers have been affected more intensely. This implies that economic and employment reactivation programs should pay special attention to the situation of youth, especially women. ECLAC figures (2021c) also reveal that people with lower levels of education suffered greater job losses: in Costa Rica the population with university education showed an unemployment rate of 13.3 percent, for those with secondary education this rate was of 18.8 , and for those who had only attended the primary level, the unemployment rate was 26.7 percent.

Reference should be made to the World Bank study (2021a) that presents an analysis of the labor market based on telephone surveys of 1,000 people from 13 Latin American countries in the months of May, July, and August 2020. The surveys were directed at people who were working before the start of the pandemic and inquired if they had lost their jobs. The results showed that in all the months the women had been affected in a more accentuated way than the men; in August 2020, the average difference of all countries in lost jobs was still 15 percent, and it was more marked in the case of permanent jobs. The percentages of job losses by sex as of May and August are shown in table 3.

Table 3. Percentages of people who had lost their jobs

\begin{tabular}{llcc}
\hline Country & & May 2020 & August 2020 \\
\hline Mexico & Women & 50 & 40 \\
& Men & 35 & 20 \\
Costa Rica & Women & 45 & 40 \\
El Salvador & Women & 65 & 45 \\
& Men & 42 & 45 \\
Guatemala & Women & 55 & 32 \\
& Men & 35 & 20 \\
Honduras & Women & 65 & 45 \\
& Men & 50 & 25 \\
\hline
\end{tabular}

Surveys revealed that having a wage job before the pandemic reduced the probability of losing a job, that is, wage employment has been a source of job security. Having an internet connection at home reduced the probability of losing the job, but only in the case of men, since women have jobs mainly in sectors that demand contacts with other people, and that are not suitable for teleworking. Other results revealed that women tended to lose their jobs due to the demands of caring for their children and other household members.

Bargain and Aminjonov (2021) used data from the personal mobility indices of urban areas of Latin American and African countries, taken from Google, to determine the impacts of the poverty rate on mobility, and of poverty on the contagion of Covid. They found that the areas with the highest rates of poverty experienced the lowest drops in mobility, which led to an increase in the number of infections. The falls in mobility were less accentuated in African countries than in Latin American ones, due to the higher incidence of poverty in the former. When measuring mobility after March 1, 2020, it is observed that in Argentina, Brazil and Colombia mobility fell drastically, showing its lowest value on March 20, 2020, while in Mexico mobility fell slowly, reaching its lowest point on April 10, 2020. As of March 20, 2020, Mexico's mobility index was 50, in relation to the starting point of March 1, when the index had a value of 100; this value was higher than that of Argentina (30), Colombia (25), Peru (20), and of the same magnitude as that of Brazil (50). The authors found that a one percent increase in personal mobility led to an increase in Covid cases on average by one percentage point; the 10 percentage point difference in poverty rates between two regions was associated with differences in the number of cases of 11 percent, as of May 3, 2020.

The authors concluded by emphasizing the importance of offering cash transfers and food to the low-income population to ensure that quarantines were effective in stopping the spread of the pandemic.

Bluedorn et al. (2021) have pointed out that there is no basis for forecasting which sectors will be the fastest to 
recover the employment levels existing prior to the crisis. Given that women have experienced the highest levels of unemployment, it will be necessary to establish mechanisms that facilitate the reincorporation of women into the labor market, such as childcare centers, flexible working hours, and training facilities in new activities.

It should be added that overcoming the crisis of the pandemic will require increases in tax revenues, not only to address the health emergency, but also for the redesign of public health and social protection networks. In this context, a recent document of the International Monetary Fund (Cardenas et al., 2021) exhorts the Latin American countries to establish as priorities the investments in the social sector areas, as well as increases in tax revenues, an exercise that should lead to the construction of a Fiscal Pact. It should be added that ECLAC (2021a) has also recommended the adoption of Fiscal Pacts by the countries of the region.

\section{Conclusions}

One of the main results of this work is that female youth unemployment does not fall in response to the increase in the Human Development Index. In other words, increases in levels of education and per capita GDP, and improvements in the health of the population, do not lead to an improvement in the performance of young unemployed women in the labor market relative to that of young male people.

The explanation could lie in "cultural" aspects that lead young women to dedicate themselves to caring for people in the home, or to housework when they are unemployed; that is, they find (unpaid) employment in "household chores". Another reason may be that the unemployed person is a single mother, which could weigh against them in the opinion of companies

Likewise, the single mother faces the restriction that taking care of her daughters or sons does not allow her to find a job with flexible working hours. The problem of young women in the labor market goes beyond the role of their human capital to find employment, since as observed in figure 1, the female youth unemployment rate does not fall due to the increase in economic growth, that is, contrary to young men, economic dynamism does not make it easier for young women to obtain a job when they are unemployed. This can denote discrimination in the labor market.

It should be emphasized that the obstacles that young women encounter in obtaining employment, whether characteristic of the labor market, or derived from the "culture" that women have certain roles to play at home, (and in companies), they have high costs in terms of domestic savings, investment and productivity rates, as well as lost economic growth, in addition to increases in the NEET population, which is conducive to increasing crime. Ostry et al (2018) have computed the increase in economic growth that developing countries could obtain as a result of the elimination of "cultural" barriers to female labor participation, at between 8 and 20 percent per year. It is valid to argue that the "culture" of abuse is one of the main causes of the decline of the Latin American economy, and of its dubious importance in the world, except in the export of primary products and people.

The situation of young women in the labor market shows that it is not enough for young persons to achieve high levels of education, but rather that institutional changes must be implemented that safeguard the work performance of young women against discrimination and gender abuse. This points to the importance of analyzing the problem of young women in the labor market on a case-by-case basis, with a view to litigating in response to gender discrimination.

Likewise, it is necessary to encourage young women to report and denounce cases of discrimination before the competent authorities with a view to initiating the corresponding lawsuits and legal processes. In other words, what is appropriate is to prosecute gender discrimination in its different manifestations and introduce the necessary changes in labor and criminal codes (and in the constitution of the republics) so that such discrimination does not enjoy impunity. As well, it is necessary to establish measures to monitor cases of gender discrimination and encourage women to report such cases with a view to filing the corresponding lawsuits. Another measure that can be effective in the business field is to promote the commitment of companies to hire and promote women who have the same qualifications as men and, in addition, to design internship programs to offer opportunities to young women who are studying university careers.

It must be considered that because of the Covid pandemic, women have suffered more pronounced job losses than men, and young women have been especially affected, as are those persons with low levels of education. It should also be noted that women tend to be less successful than men in returning to their old jobs.

Hence the importance of making efforts to prevent gender gaps from widening in the region as a result of the Covid pandemic. Actions to achieve this objective would be, in the first place, the creation of national networks of childcare centers, as well as the expansion of bonus programs conditional on children not dropping out of school, and financial assistance aimed at women microentrepreneurs. Otherwise, growing gender gaps would 
undermine economic reactivation efforts, as well as governance and economic growth. The experience of several countries (Canada, Scandinavian and EU countries) shows the great value in the establishment of national networks of childcare centers, which would help to facilitate employment, as well as the continuation of studies of single mothers.

The importance of protecting children from the repercussions of the pandemic must be underlined. The World Bank (2021b) has warned that this population in its early age has a critical vulnerability to the pandemic since the deprivations of health, education, motivation, stimulation, and care, can lead to them in their adulthood suffering from problems such as low cognitive and behavioral performance. This organization recommends giving priority to the food security of children, as well as the prevention of violence and abuse that children tend to suffer in times of crisis.

It should be noted that the ease of firing male and female employees has been described as a "virtue" of the labor legislation of the corresponding country, but the evidence shows that unemployment leads to the growth of the NEETS population, to the falls in employment rates, savings and investment and labor productivity, and therefore economic growth, and thus to the growth of violence, elements not considered in labor economy theories. At this point, the evidence must be brought into account that people who experience unemployment tend to die at an earlier age than people who do not go through this trauma (Junakar, 1991), therefore, the "virtue" of a labor market that facilitates the unemployment of women and men constitutes in fact a "virtue" of mass extermination, and a violation of the human rights of the people involved, as Article 3 of the Universal Declaration of Human Rights advocates that:

\section{Everyone Has the Right to Life}

An appropriate policy would be that, in times of crisis, or of slow economic growth and low aggregate demand, the state partially covers the payroll of companies, protecting employment and the family, thus protecting youth and therefore the future. of the country. This of course requires considerable increases in tax revenues, which represents a challenge in the face of Latin American countries' high tax evasion, and the reluctance of certain power groups to pay taxes. ECLAC (2019) has indicated that on average, large companies in Latin America pay only 4 percent in income tax. This organization has described these practices as manifestations of the "culture" of abuse and privilege that prevails in Latin America. To this must be added the false news that taxation discourages investment, which provides the culture of abuse an additional pretext for not increasing taxation and avoiding paying taxes. In this way, greed, and zombie ideas, in the sense of Krugman (2020), thus constitute the true "dead weight" for society and the economy, which indicates the convenience of purging or exorcising Economics from "theories" (or rather, paid advertisements), that are no more than reflections of greed from the voracity of interest groups. But the zombie ideas have a "dynamic" character in that they generate their antithesis in violence and crime, which have a higher cost than the "savings" due to tax evasion and low taxation. But the youth deserve much better than fake news and science fiction theories that try to pass as Economics.

\section{References}

Apap, W., \& Gravino, D. (2016). A Sectoral Approach to Okun's Law. Applied Economic Letters, 24, 319-324. https://doi.org/10.1080/13504851.2016.1186789

Ball, L., Leigh, D., \& Loungani, P. (2013). Okun's Law: Fit at Fifty? NBER Working Paper 18668. https://doi.org/10.3386/w18668

Banerji, A., Huidan, L., \& Serrgejs, S. (2015). Youth Unemployment in Advance Europe: Okun's Law and Beyond. IMF Working Paper 15/5. International Monetary Fund. https://doi.org/10.5089/9781498382519.001

Bluedorn, J., Francesca, C., Niels-Jakob, H., Ippei, S., \& Marina, M. T. (2021). Gender and Employment in the Covid-19 Recession: Evidence on "She-cessions. IMF Working Paper 21/95. https://doi.org/10.5089/9781513575926.001

Buehn, A., \& Friedrich, S. (2012). Shadow Economies Around the World: Novel Insights, Accepted Knowledge, the New Estimates. International Tax and Public Finance, 19, 139-171. https://doi.org/10.1007/s10797-011-9187-7

Cáceres, L. R. (2008). Que Variables Determinan el Índice de Desarrollo Humano en los Países de América Latina? Comercio Exterior.

Caceres, L. R. (2017a). Essays on Shadow Economies in Latin America. Lambert Academic Publishing.

Caceres, L. R. (2021a). Causes and Consequences of Idle Youth in Guatemala. International Journal of 
Economics and Finance, 13(1). https://doi.org/10.5539/ijef.v13n1p61

Caceres, L. R. (2021b). Youth Unemployment in Honduras. International Journal of Economics and Finance, 13(2). https://doi.org/10.5539/ijef.v13n2p61

Caceres, L. R. (n. d.). Ninis in Latin America. Unpublished.

Cáceres, L.R. (2017b). Self-Employment in Latin América. Journal of Developing Areas.

Caporale, G. M., \& Gil-Alana, L. (2014). Youth Unemployment in Europe: Persistence and Macroeconomic Determinants. Comparative Economic Studies, 56, 581-591. https://doi.org/10.1057/ces.2014.29

Cárdenas, M., Rafael, de H., \& Miguel, S., (2016). Idle Youth in Latin América: A Persistent Problem in a Decade of Prosperit. Economia, 5, 1-40.

Cardenas, M., Ricci, L. A., Roldos, J., \& Werner, A. (2021). Fiscal Policy Challenges for Latin America During the Next Stages of the Pandemic: The Need for a Fiscal Pact. IMF Working Paper 21/77. https://doi.org/10.5089/9781513574332.001

CEPAL. (2019). Fiscal Panorama of Latin America and the Caribbean, Santiago de Chile, CEPAL.

CEPAL. (2021a). Panorama Social de America Latina y el Caribe.

CEPAL. (2021b). La Autonomía Económica de las Mujeres en la Recuperación Sostenible y con Igualdad.

CEPAL. (2021c). Balance Preliminar de la Economía Latinoamérica y del caribe en 2020.

Chioda, L. (2016). Stop the Violence in Latin America. Washington DC, World Bank.

Choudhry, M. T., Marelli, E., \& Signorelli, M. (2012). Youth Unemployment Rate and Impact of Financial Crisis. International Journal of Manpower, 33, 76-95. https://doi.org/10.1108/01437721211212538

Cunningham, W. (2009). Unpacking Youth Unemployment in Latin America. World Bank Working Paper 5022, Washington DC. https://doi.org/10.1596/1813-9450-5022

Giuliano, P., \& Antonio, S. (2009). Growing Up in a Recession: Beliefs and the Macroeconomy. NBER Working Paper 15321. https://doi.org/10.3386/w15321

Hutengs, O., \& Stadtmann, G. (2014). Don’t Trust Anybody Anybody Over 30: Youth Unemployment and Okuns Law in CEE Countries. Bank I Kredyt, 45, 567-580. https://doi.org/10.1057/ces.2014.22

Junakar, P. N. (1991). Unemployment and Mortality in England and Wales: A Preliminary Analysis. Oxford Economic Papers, 43, 305-320. https://doi.org/10.1093/oxfordjournals.oep.a042001

Krugman, P. (2020). Arguing with Zombies. W. W. Norton, New York.

Meyer, D. (2017). The Impact of Remittances on Economic Growth. Economica, 18, 147-155. https://doi.org/10.1016/j.econ.2016.06.001

Ostry, J., Alvarez, J., Espinoza, R., \& Papageorgiou, C. (2018). Economic Gains from Gender Inclusion: New Mechanisms, New Evidence. Staff Discussion Note 18/06, International Monetary Fund, Washington DC. https://doi.org/10.5089/9781484337127.006

Parker, S., \& Emmanuel, S. (2004). The Added Worker Effect Over the Business Cycle: Evidence from Urban Mexico. Applied Economics Letters, 11, 625-630. https://doi.org/10.1080/1350485042000235693

Paz, J. (2009). El Efecto del Trabajador Adicional: Evidencia para Argentina (2003-2007). Cuadernos de Economía, 46, 225-241. https://doi.org/10.4067/S0717-68212009000200005

Ryan, P. (2001). The School-to-Work Transition: A Cross-National Perspective. Journal of Economic Literature, 39, 34-92. https://doi.org/10.1257/jel.39.1.34

Saadi, T., \& Rui, X. (2010). A Vicious Cycle: How Pandemics Lead to Economic Despair and Social Unrest. IMF Working Paper 20/216, 2020, International Monetary Fund. https://doi.org/10.5089/9781513559162.001

Torres, J., \& McKenzie, L. (2020). Youth Unemployment in Uruguay. IMF working paper 20/281, Washington DC. https://doi.org/10.5089/9781513563947.001

World Bank. (2021a). The Gendered Impacts of COVID-19 on Labor Markets in Latin America and the Caribbean. Gender Innovation Lab, World Bank.

World Bank. (2021b). 15 Ways to Support Young Children and their families in the COVID-19 Response. 
Zhengxi, L., Yates, J., \& Picot, G. (1999). Rising Self-Employment in the Midst of High Unemployment: An Empirical Analysis of Recent Developments in Canada. Statistics Canada, Research Paper Series.

\section{Copyrights}

Copyright for this article is retained by the author(s), with first publication rights granted to the journal.

This is an open-access article distributed under the terms and conditions of the Creative Commons Attribution license (http://creativecommons.org/licenses/by/4.0/). 